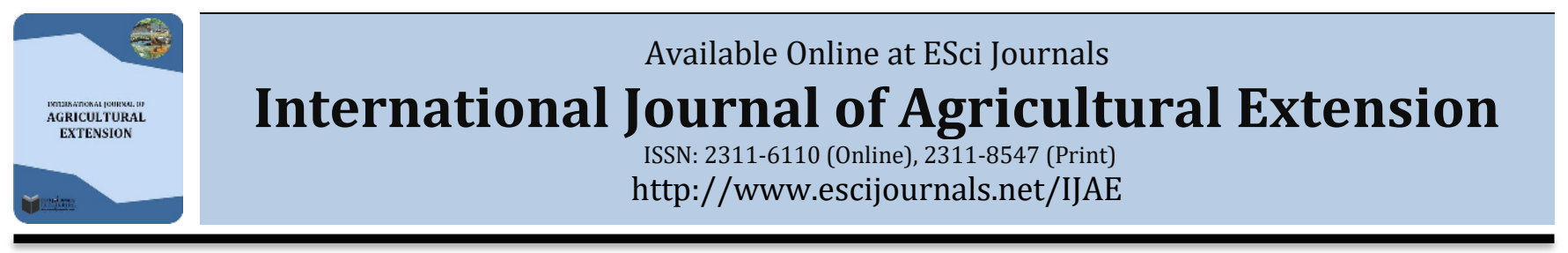

\title{
WOMEN FARMERS' ADOPTION CHALLENGES ON ARTIFICIAL INSEMINATIONS SERVICE IN OUTSKIRT OF ADDIS ABABA
}

\author{
Beliyu Limenih \\ Socio - Economics, policy, Extension and Gender process, Ethiopia Environment and Forest Research Institute, Addis \\ Ababa, Ethiopia.
}

\section{A B S T R A C T}

The study was conducted in purposively selected Oromia National Regional State aiming at to suggest strategies to better involve women farmers in Artificial Insemination service. Experts from office of livestock and fishery represented the study population. Group discussion were undertaken separately for Women and men farmers. Collected information was analyzed qualitatively and interpreted accordingly. The study found that institutional and cultural barriers hindered many number of women AI (Artificial Insemination) technicians less involved in AI service delivery. Specifically, institutions don't encourage women applicant to apply on AI, they thought the position is full of hardship and risky for women to give a service basing in rural areas. In addition to that, the service needs some physical fitness and it would be more difficult for women to move long distance caring containers. Moreover, there is animal disease (brucella) that can be easily transmit to human and can cause gynaecological problem for women. Culturally, even if it is not boldly pronounced by the community, there is a feeling of indignity when women provide AI services. On the other hand, the community also ashamed women farmers, if they ask AI service provision. Moreover, culturally women farmers are not allowed to watch inseminations service. So, in order to increase number of women AI technicians: nominating women technicians from local communities (at least grade 8 completed) and animal science graduate, and train more in practical way would made women AI technicians to be more capable. Support women AI technicians to work privately through post payment service for a while, would raise women acceptance by community. In order to increase number of women farmers attendees on training: conduct on farm training, invite women farmers directly for training, organize training between march to May seasons, prepare pictured based training (including production manuals) would change the number of women dairy producer on AI service provision.

Keywords: Artificial Insemination, AI service, women, institutional, cultural barriers.

\section{INTRODUCTION}

Ethiopia is one of the least developed countries in subSaharan Africa with large potential in livestock population, being $1^{\text {st }}$ in Africa and $9^{\text {th }}$ in the world. However, the dairy industry is not developed as that of other East African countries such as Kenya, Uganda and Tanzania. The cattle population in Ethiopia is estimated to be 41.5 million heads comprising $99.4 \%$ indigenous (Zebu), $0.5 \%$ crossbreeds and $0.1 \%$ exotic breeds which are mainly kept under smallholder subsistence farming (EASE, 2003). Out of the total cattle population 22.9 million are found in oromiya regional state (CSA, 2011).

* Corresponding Author:

Email: beyebebe@yahoo.com

(C) 2018 ESci Journals Publishing. All rights reserved.
Dairy-cows are estimated to be around 6.7 million and milking-cows are about 10.7 million heads during the reference period $(2012 / 13)$. The subsector contributes about $16.5 \%$ of the national Gross Domestic Product (GDP) and $35.6 \%$ of the agricultural GDP. It also contributes $15 \%$ of export earnings and $30 \%$ of agricultural employment (Leta, 2014). The Oromia region contributes about $44 \%$ of the total annual milk produced in Ethiopia (LIVE, 2014). Zebu (Bos indicus) cattle are multipurpose animals with low potential for meat and milk production which is estimated to meet only $35 \%$ of the human requirements (Landiver et al., 1985; Mukasa-Mugerewa, 1989). Oromiya region has 229 Artificial Insemination (AI) clinics to serve surrounding farmers. Currently, the services are being 
delivered by 665 male and 2 women governmentally employed AI technicians. Surprisingly there are only seven private limited company that provide AI services. Out of it only two are owned by women.

In the region women farmers have limited access to AI service than men. As a strategy the institution has set a plan to address $30 \%$ of women farmers from the total number of beneficiaries. However, according to Oromiya Bureau of Livestock and Fishery (BoLF) 2016 report out of 1197 AI service accessed only 206 were women headed farmers. On the other word, the service approached $17 \%$ of women farmers. The reason was majority of AI technical are male and have better access to communicate with male farmers than women. For instance, male farmers frequently go to city and have better access to have current information than women farmer. On the other hand, majority of male farmers have mobile phone can easily call to AI technicians as they needed.

Beside that some thoughts also affected both women and men farmers access from the service. Around Jimma area, some of community member thinks that practicing $\mathrm{AI}$ as "against God willing". Men are the predominant dairy animal owners and women perform the majority of the work with dairy cows and are their day-to-day activities. Women are the most likely household member to observe a heat, and to be at home when an AI technician provide services. However, cultural barriers can inhibit women's active participation in the process. Women may be uncomfortable discussing AI with male technicians and men may be uncomfortable with their mothers, daughters or wives interacting with male AI technicians. These affected an efficiency of AI services. To improve on-farm management of dairy cows and address the existing barriers to higher conception rates, women must be empowered with the necessary knowledge and skills to build their expertise on dairy animal management and reproductive fitness. Evidences also indicate that women AI technicians outperform men at achieving positive pregnancies. So, engage women in AI service delivery, and improve women farmers access to AI service, suggest women specific pedagogical and training needs as well as gender related issues that feed AI technicians and whole farm management training curriculums upgrading process, customer service delivery approach sensitive to the needs of women farmers, propose feasible strategies/entry points for cultivating buy-in for women AI technicians across stakeholders (community/farmers, private institutions, GO and NGOs), Suggest strategies for ensuring women AI technicians long-term sustainability in managing their businesses ,recommend options on how dairy hubs, cooperatives, processors and private sector partners should be supported to provide women equal access to pre-payment schemes for $\mathrm{AI}$ and other cattle development services.

\section{MATERIALS AND METHODS}

The study was conducted in Oromiya Regional State in three selected weredas, namely, Welmera, sululta and Ada's. The study areas were selected purposively based on dairy production and AI service experience in the region. Consultation with Oromiya office of livestock 80 farmers were selected purposively based on their experience on AI services. Out of it, half of them were women households. Moreover, by using simple random sampling 18 AI technicians were interviewed. A total of four dairy cooperatives and product processors interviewed. To complement the existing information's 3 OOLF directors were interviewed.

A total of four group discussions (FGD) were organized. Women and men FGD were undertaken separately in each district. Moreover, dairy cooperatives/union and AI technicians were selected purposively from each district. Two dairy processors were interview at Ada's district. A cross-sectional type of study supported by semi structured questioner survey (Key Informant Interview), observation, focus group discussion (proportional pilling, and T-table) was carried out. The collected information were summarized and interpreted. Moreover, Harvard Analytical Frameworks (HAF) and Moser tools were also used to summarize Focus Group Discussion information.

\section{RESULT AND DISCUSSION}

Gender division of labour: From a study it was found that, calf management including feed collection, feed preparation, feeding, watering, health care, keeping, buying medicine, washing and barn clearing activities were undertaken by adult women. In heifer and dairy cow's management, daughters had high engagement on grazing, watering, heat detection and mating of the animals in the field than women adult. As reported by farmers, in this day's most children are student and couldn't able to engage on farm activities on daily. Regarding milking, barn clearing, preparing dung cake and household works are always undertaken by women adult. And on general farm management barn 
construction and maintenance activities are frequently accomplished by men adult. Even if women adults participate on communities' works (terrace construction) men adults participate on local meeting, school meeting, and community works more frequently than women adult. As farmers said, through this all activities barn cleaning, milking and household activities took much of women times. On the other hand, barn construction and feed collection were highly time taking activities for men farmers. Consulting with farmers, based on farm activities three seasons were identified in the region namely main season (June-October), belg (march-may), and belg (harvesting time) (NovemberFebruary). As farmers said at belg (march-may) and main season (June-October) are the average daily work hours of women and men daily activities hours decreased and increase. All in all the average daily work hours of women and men with in seasons were 10 and 6 hours per day. And at main season the maximum working hours of women and men will be raise to 14 and 8 hours per day. Women farmers have said that there is a positive relation when adopting crossbreed cows with an increment of role and responsibilities at household level. Because, crossbreed cows demand intensive management and health care than local breed cows.

The increased responsibility includes;

Feeding and feed preparation: Even if the productivity of crossbreed cows is higher than local cows. Equivalent to that, they need to feed every 3-4 hours. That increased women frequency of feed preparation and feeding hours per day.

Barn clearing: Women clean barn daily. As they said before the introduction of crossbreed cows it takes 30 minutes but now it took around 1:30 to 2 hours per day.

Keeping cross breed cows: Cross breed cows can easily affected by diseases than local breeds. It increased women frequency of follow up at home.

Social life and participation: The routine management of cross-breed cows (the increased workload) has brought severe time constraint on women. This in turn reduced their participation in social events, and trainings/meetings. Men increased responsible included: Barn construction: crossbred cows demand a wellstructured (recommended) barn than local cows. So, men farmers were modified the existed barn and built additional barn for cows. If it is not they can easily caught by disease.
Purchasing different feeds: crossbreed cows should get different nutritious feeds than local cows. It increased frequency of purchasing animal feeds.

Taking to clinic: Crossbreed cows are sensitive to diseases. So men farmers take cow to animal clinic more frequently than local cows.

Access to and control over key productive resources: As shown in Table 1, almost 34.5, 50 and $15.5 \%$ of the people are found on poor, middle and rich societies. And key resource like land, farming tools, dairy cows, heifers, and calves, income from crop sale, credit/loan and equines are highly accessed by men and except middle income households all are controlled by men. Similarly, in all households, men were totally accessed on extension services and trainings opportunities and decides when and how to use AI service provision. On the other hand, selling milk, income from milk and milk products accessed and controlled by women in all household. From focus group discussion, women and men were controlled some of the income (25\%) and most of the income $(75 \%)$ in the study area. Majority of women have less access on agricultural training. As women farmers said (welmera), only research institutes organized a training to women farmers. Moreover, because of household work burden, they couldn't able to participate on training. On the other hand, men farmers were reflected that they would not allowed their wife to participate on a trainings, they assumed that women can't able to write and read, and not capable to understand the information and transfer the knowledge to household members and women couldn't able to take cows for AI service. So men most of the time take cows to animal health clinic (for synchronization).

\section{Barriers, constraints and challenges}

Technical capacity development: As farmers said, 6080 number of Women farmers participated on average two times a year on dairy management and off season production with drip irrigation training that was organized by research institute (welmera). However, on agricultural package, livestock management, peace and security, forest and natural resource management (watershed development), pest and disease control, income and cost analysis and saving and credit majority of men were participated in theses regard. Low participation of women were happened because of approach (men have mobile phone and can be easily get by development agents) and participate accordingly. 
Table 1. Access to and control over key productive resources.

\begin{tabular}{|c|c|c|c|c|c|c|c|c|c|c|c|c|c|c|c|c|c|c|}
\hline \multirow[b]{3}{*}{ Resource, service and benefit } & \multicolumn{6}{|c|}{ Poor household (34.5\%) } & \multicolumn{6}{|c|}{ Middle income HH (50\%) } & \multicolumn{6}{|c|}{ Rich /better of HH (15.5\%) } \\
\hline & \multicolumn{3}{|c|}{ Access } & \multicolumn{3}{|c|}{ Control } & \multicolumn{3}{|c|}{ Access } & \multicolumn{3}{|c|}{ Control } & \multicolumn{3}{|c|}{ Access } & \multicolumn{3}{|c|}{ Control } \\
\hline & 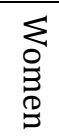 & $\begin{array}{l}Z \\
\mathbb{D}\end{array}$ & $\begin{array}{l}\mathscr{\sigma} \\
\stackrel{f}{f}\end{array}$ & 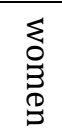 & $\begin{array}{l}Z \\
\mathbb{D}\end{array}$ & $\begin{array}{l}\text { g } \\
\stackrel{+}{+}\end{array}$ & $\begin{array}{l}\sum \\
\$ \\
\$ \\
\mathbb{8}\end{array}$ & $\begin{array}{l}Z \\
\mathbb{D}\end{array}$ & $\begin{array}{l}\stackrel{g}{0} \\
\stackrel{+}{F}\end{array}$ & $\begin{array}{l}\Sigma \\
0 \\
\Xi \\
0\end{array}$ & $\stackrel{3}{9}$ & $\begin{array}{l}\text { g } \\
\stackrel{+}{z}\end{array}$ & 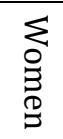 & $\begin{array}{l}Z \\
\mathbb{D}\end{array}$ & $\begin{array}{l}\text { g } \\
\stackrel{+}{=}\end{array}$ & $\begin{array}{l}\Sigma \\
\varrho \\
\Xi \\
\Xi \\
\Xi\end{array}$ & $\begin{array}{l}\bar{Z} \\
\stackrel{0}{g}\end{array}$ & $\begin{array}{l}\stackrel{g}{0} \\
\stackrel{+}{+}\end{array}$ \\
\hline Land & & Men & & & Men & & & Men & & & Both & & & Men & & & Men & \\
\hline Farming tool & & Men & & & Men & & & Men & & & Both & & & Men & & & Men & \\
\hline Dairy cows & & Men & & & Men & & & Men & & & Both & & & Men & & & Men & \\
\hline Heifers & & Men & & & Men & & & Men & & & Both & & & Men & & & Men & \\
\hline Calves & & Men & & & Men & & & Men & & & Both & & & Men & & & Men & \\
\hline Equines & & Men & & & Men & & & Men & & & Both & & & Men & & & Men & \\
\hline Selling Milk and milk products & & Women & & & & & & Women & & & & & & Wome & & & & \\
\hline Income from sale of raw milk & & & & & Women & & & & & & Women & & & & & & Women & \\
\hline Income from sale of milk products & & & & & Women & & & & & & Women & & & & & & Women & \\
\hline Income from crop sale & & & & & Men & & & & & & Both & & & & & & Men & \\
\hline Income from cattle sale & & & & & Men & & & & & & Both & & & & & & Men & \\
\hline Training ,field visit & & Men & & & & & & Men & & & & & & Men & & & & \\
\hline Credits /loan & & Men & & & Men & & & Men & & & Both & & & Men & & & Men & \\
\hline Livestock/dairy extension service & & Men & & & & & & Men & & & & & & Men & & & & \\
\hline Animal health service & & Men & & & & & & Men & & & & & & Men & & & & \\
\hline Participate AI service in the $\mathrm{HH}$ & & Men & & & & & & Men & & & & & & Men & & & & \\
\hline
\end{tabular}

And because of workload in the household and place of a training hinders women from participating on a training (sululta). Moreover, husband/men assumed women can't able to transfer the knowledge and skill gained from training to the family because they lack understanding and couldn't able to write and read (low level of literacy

AI and other dairy development services: Women farmers were impeded from AI services because of less access on information (men have better access on information than women). Besides that the communities ashamed her if she ask AI service provision. Moreover, women are not allowed to watch insemination for cultural reason (sululta). Because of that AI training were provided only for men farmers. That may hinder the number of women participation at AI service (welmera).

\section{Gender needs and priorities}

Training and pedagogical: Before conducting training, women should be directly invited for training. Moreover, before the actual training, the trainer should prepared picture based materials rather than focusing on theoretical issues. Since they have cows and a lot of household responsibilities they need to train not more than 5-6 hours. And at on-farm training, morning at 4-6 am would be an appropriate time for them. Men suggested practical and on station training types for women farmers. 
Table 3. Gender specific needs/priorities of women and men in relation to dairy cattle husbandry and management and AI services (Moser tool).

\begin{tabular}{|c|c|}
\hline Women & Men \\
\hline $\begin{array}{l}\text { - Animal nutrition (they couldn't able to know what kinds of } \\
\text { feeds are important for dairy cows and amount) } \\
\text { - Milk preserving methods (perishable sometimes) } \\
\text { - Milk processing and value addition (better price) } \\
\text { - Milk marketing (because they are selling by unfair price) } \\
\text { - AI service } \\
\text { - Identification of heat periods } \\
\text { - Pre-prevention techniques of disease (breast disease) } \\
\text { - Disease symptoms and treatment }\end{array}$ & $\begin{array}{l}\text { - Animal Feed (they lack where they should buy } \\
\text { and how to produce forage crops) } \\
\text { - Barn construction (design and build local } \\
\text { material) } \\
\text { - Adopting crossbreeds (identifying the nature and } \\
\text { behavior) } \\
\text { - AI service } \\
\text { - Breeding (AI techniques) } \\
\text { - Health (animal disease and symptom) }\end{array}$ \\
\hline
\end{tabular}

Perception on women AI technicians: In a case of Sululta, it was unveiled that respondents were getting AI service from women AI technicians. While she provides a service she also provides advisory services regarding heat detection. According to male technicians, all farmers have said that at male headed households they will not be entered if husband is not at home.

Because, men support him at AI service provision time, paid better price per service than women's dose and AI technicians have better relationship with men/husband, so they always preferred for service provision male households than women headed households.

On the other hand, farmer's believed that more women AI technicians' presence will improve the current AI service provision in the area. They assumed, women do care for everything by their nature, and women farmers can easily communicate with women AI technicians than their men counterparts.

Gender related constraints in AI service: Each AI technicians covered 6-8 peasant association in a given districts. Majority of them provide the service by using motorbike. However, they don't have sufficient budget for fuel and maintenance. Because of that they couldn't able to provide the service as expected. They also said that they have been providing the service fairly for women in male headed household and women in female headed household. In addition to that there is no any gender, cultural and social barriers that impede them to provide the service to women dairy producer. However, they confirmed that majority of the beneficiaries from service are male farmers. It was due to male dairy producers took them from their office for AI service and easily communicate with male headed household.

Engagement and acceptance of women AI technicians: AI technicians said that during recruitment the institution less encourage women applicants to participate in AI training. Because of that, women psychologically afraid to engaged on this profession. The other thing is that, if well aware women need to engage on a sector, access of educational opportunities is very low. Moreover, tuition fee is unaffordable for self-sponsors. They also said that if women engaged on the service, they might face low acceptance by the community regarding their service provision. In addition to that, having low acceptances by family, travel caring containers, riding motorbike, and providing the service at night would be a challenge for them to survive on the sector. On the other hand, women by their nature are patient, carefully accomplish skill demanding activities, and fast accomplishment nature of them would be good opportunities to provide AI service very efficiently than men technicians. Additionally, women dairy producer can easily communicate with women AI technicians than men. These kinds of relation can create women dairy producers to consult other development agendas with women AI technicians. Even if they don't have experience working with women AI technicians, they believed women can change community's perception through demonstrable performance.

\section{Dairy cooperative and unions}

Access to AI and breed improvement services: It has been 1-18 years since they are established as a cooperative/union. The cooperatives have a minimum and maximum of 23 and 1375 members, $34 \%$ of them are women. Even if Biftu Berga (Welmera) cooperative has its own AI technician, it couldn't able to provide AI service for members because of semen and nitrogen 
shortage. So, currently all cooperatives member have been getting AI service from public AI technicians through payment. They have complained less accessibility of nitrogen and semen, semen quality, lack of skill and experience of AI technicians, and inefficient service provision of the current AI service provision. According to the service provision, cooperatives heads said that there is no any difference for both women and men members. Even if there is no any challenge for men AI technician's to approach women farmers, women farmers afraid to watch insemination.

Engagement and acceptance of women AI technicians: All cooperatives don't have experience in AI service provision by women AI technicians. But they believe that more women AI technicians should be engaged on the sector. In order to promote women AI technicians they suggested that advocacy at ATVET (Agricultural training vocational Education Training) colleges and community level might help women awareness to be changed and encouraged to engage on AI services. Moreover, minimizing the current challenges and creating conducive environment like incentives, salary improvement, fulfilling basic facilities, availing women motorbike and allocating sufficient budget for the service provision might encourage more women engagement.

According to community's perception, they have said that communities have animal health services from women veterinary doctors. But what they afraid are since women AI technicians are not common in the area, communities might lack confidence on women service provision. So, women should break this distrust through outstanding performance on service provision. To have professional qualities, they believe that women should be well equipped through practical and theoretical trainings. Finally, they believe that women by their nature are active, carefully accomplished skill demanding activities and highly responsible than men. So they are willing and believed will get better service if more women AI technicians engaged on the service.

Customer service approach for AI service: All cooperatives have positive attitudes towards post payment arrangement for dairy producers. As they said, they always made payment twice a month. So, they are positive to arrange long term credit system to milk producers from sold milk price. And they are willing to arrange and manage the service through office provision Dairy processing industries Suppliers profile and their access to AI service: The dairy processing industries have average number of 100-215 milk suppliers. From that around 60-80 number of a supplier are women dairy producers. Even if they have been receiving milk from primary cooperatives they don't have a separate data base for member suppliers. Milk processor have a milk processor machine that can process 4000-15,000lt of milk. However, they only process 6000-4500lt of milk per day. As the processing heads said that, all have their own AI technicians that provide AI services for member and nonmember dairy producers freely (Gensis Farm). In addition, they provide health service, access to feed, water provision, advisory services (they advise on dairy husbandry, calving assistance and milk quality and management), technical support (this includes hooftrem and delivery (operation) services) and oxen gift (hard worker member for breeding purpose).

Through this all provision the processing industries doesn't have a special treatment for women except providing expensive medicine through long term return system for less capacitate women dairy producers. The reason was that, almost all women dairy producers are well capacitated and they don't need any special treatment than men member. Moreover, the area is found near to town this favored member women can easily access AI service provision easily (Ada's wereda).

Engagement and acceptance of women AI technicians: All processing industries do not have an experience working with women AI technicians. But they have positive attitude on the engagement of women on AI service. As they said, they have an ample experience on women veterinarians that have been working on animal health service in the area. Moreover, the industries encouraged women expertise involvement on different department. For instance, at Genesis farm four department heads are women out of five. About community's perception on engagement of women on AI service, they said that, communities might lack confidence on women AI service. But they surely said it would not be a serious challenge if women engaged on the service.

To improve community's attitudes towards women AI technicians, the industries believed that women professional should change their attitudes and engaged themselves on the service. And to improve their acceptance, they are very happy to offer attachment opportunities for women AI student for longer times. And the processing industries will gives priorities for 
women AI technicians at recruiting times

Customer service approach for AI service: The interviewed firms are very happy to provide AI service with a collaboration of other agencies. As they said, they already have enough materials including motorbike and Bajaj for transportation purposes. Moreover, they are very much ready to provide office for AI technicians for on stationed services.

Government actors (regional and district livestock bureaus)

Engagement and acceptance of women AI technicians: As they said, currently four women AI technicians are engaged on the region. Reason of less number of women AI technician's engagement on the sector includes:

-Institutional -the institution don't encourage women to apply for the position. They think that the position is full of hardship especially women couldn't able to move alone at night time. In addition to that, the service needs some fiscal fitness to able to move caring those containers and ride motorbikes. Moreover, there is animal disease (brucella) that can be easily transmitted to human and can directly cause gynecological problem on women.

-Culturally: even if it is not boldly pronounced by a community there is a feeling of indignity when women provide AI services. This humiliation hindered women professionals not engaged on this sector. Moreover, in many rural places it is not common and accepted when women ride motorbike. So this discouraged women to participate on this discipline. On the other hand, the communities have an experience on gaining animal health services from women veterinarians. They will accept if more AI service providers participated on the sector. Because, there is a feeling that women are more patient, efficient and clearly accomplish skill demanding profession like AI service than men.

\section{CONCLUSION}

Farmers reported that the average daily work hours of women and men daily activities hours on Belg (marchmay) minimized, whereas in a main season (JuneOctober) raised rapidly. And the other thing is that, because of household work burden, women farmers couldn't able to participate on training. Moreover following crossbreed cows adoption women farmers' social life and participation decreased. Male farmers reflected that they would not allowed their wife to participate on a trainings. Cause of a fear on women can't able to write and read, and less capable to understand the information and transfer the knowledge to household members. So, to raise the participation of women on training the OOLF (Oromiya office of livestock and fishery) should organize trainings between marchMay seasons. In addition to that supporting a training through audio visual material would advance the level of women undertaking. Majorities of women have mobility limitation, so conducting a training near to their station would increase number of participant farmers. Women farmers were impeded from AI services because of less access on information (men have better access on information than women). In order to increased women participation the OOLF (Oromiya office of livestock and fishery) should conduct awareness creation at community meeting time and public ceremony. And, organize frequent field days on demonstrated activities. Moreover, the project should seriously follow the number of beneficiaries (women and men farmers).

On the other hand, farmer's believed that more women AI technicians' presence will improve the current AI service provision in the area. They assumed, women do care for everything by their nature, and women farmers can easily communicate with women AI technician's than men technicians. In order to increase women AI technician's engagement the OOLF should nominating women technicians from local communities (grade 8) and animal science graduate, and train more in practical way would made women to be capable.

To improve community's attitudes towards women AI technicians, women professional should change their attitudes and engaged themselves on the service. Oromiya office of livestock and fishery should arrange student attachment with dairy processing industries for women AI technicians before entered to communities. Moreover, after School arranging refreshment courses and experience sharing for them will enhance their capacities and confidence. If it is possible, the project encourage and support women AI technicians to provide service provision through credit system till the communities build trust on their services.

Acknowledgement: First I like to thank my almighty God for everything. I would like to extend my heartfelt thanks to Land O'lake project (public private partnership) for sponsoring the project. I keep going my thanks to Mr. Mulugeta Kassa for his helpful comments on this research paper for devoting their precious time. And I would like also thank Daniel Ayele in Holetta 
Agricultural Research Center for assisted me in data collection with patience, commitment and dedication and facilitating every arrangement required for the study. Finally, I need to thank Welmera, sululta and Ada district Office of livestock and fishery personnel, farmers and dairy cooperatives who responded to all questionnaires with patience and gave basic information for this research work.

\section{REFERENCES}

Anderson JR, Feder G. (2003). Rural Extension Services', World Bank Policy Research Working Paper 2976, World Bank, Washington D.C. http://econ.worldbank.org/files/24374_wps2976 .pdf.

Birkhaeuser D, Evenson RE, Feder G (1991). The Economic Impact of Agricultural Extension: A Review', Econ. Dev. Cultural Change, 39,607-650.

CSA Report of federal Democratic Republic of Ethiopia (2011). Static report on socio-economic characteristics of the population in agricultural households, Land use, Area and production of crop. Addis Ababa: CSA, 141-169.

Odame HH, Hafkin N, Wesseler G, Boto I (2002). Gender and Agriculture in the Information Society. International Service for National Agricultural Research Briefing Paper No.55. The Hague, The Netherlands: ISNAR.

Ozowa, V.N. (1995). Information Needs of Small Scale Farmers in Africa: The Nigerian Example. Quarterly Bulletin of the International Association of Agricultural Information Specialists, IAALD/CABI 40 (1).add page numbers here

Rajak TA (1990). Improving the relevance and effectiveness of agricultural extension activities. Available at: www.fao.org/docrep/v4805e/v4805e07.htm.
Telecommons Development Group (2000). Rural access to information and communication technologies (ICTs): The challenge for Africa (Draft). African Connection Secretariat.

Webb D.W. (2003). Artificial Insemination in Cattle. University of Florida, Gainesville. IFAS Extension, DS 58. Pp. 1-4.

Yemane B., Chernet T., Shiferaw T. (1993). Improved Cattle Breeding. National Artificial Insemination Centre. Addis Ababa, Ethiopia. Pp. 15.

Zewde E. (2007). Artificial insemination and its implementation. Ethiopian Society of Animal Production (ESAP). Addis Ababa, Ethiopia., 7-14, $29,45$.

Welch CJ, Alemu B, Msaki T, Sengendo M, Kigutha H, Wolff A. (2000). Improving Household Food Security: Institutions, Gender, and Integrated Approaches. U.S.A: BASIS Management Entity.

World Bank (2001). Engendering Development through gender equality in Rights, Resources and Voice. World Bank Policy Research Report 21776. Washington, D.C. and London: World Bank and Oxford University Press.

Zewdie E., Deneke N., FikreMariam D., Chaka E., HaileMariam D., Mussa A.(2005). Guidelines and procedures on bovine semen production. NAIC, Addis Ababa.

Zewdie E., Mussa A., Melese G.M., HaileMariam D., Perera B.M.A.O. (2006). Improving artificial insemination services for dairy cattle in Ethiopia. In: Improving the reproductive management of smallholder dairy cattle and the effectiveness of artificial insemination services in Africa using an integrated approach. International Atomic Energy Agency (IAEA). Pp. 17-19. 